\title{
Ditames Éticos e Jurídicos na Relação do Médico com as Redes Sociais: Quantos “Likes” Eu Mereço?
}

\section{Ethical and Legal Dictates in the Doctor's Relationship with Social Networks: How Many "Likes" do I Deserve?}

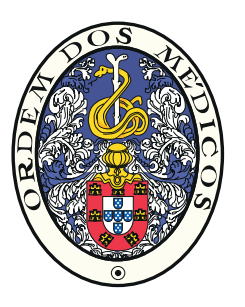

Carlos DURÃO $₫ 1$, Rafael da Costa BRAZ LAMARCA ${ }^{2}$

Acta Med Port 2018 Sep;31(9):449-450 - https://doi.org/10.20344/amp.9392

Palavras-chave: Médicos; Social Media

Keywords: Physicians; Social Media

\section{INTRODUÇÃO}

Os avanços tecnológicos associados aos meios informacionais alteraram substancialmente a forma de «estar no mundo» ${ }^{1}$ a partir do final do século $X X$ e, atualmente, inúmeros apetrechos electrónicos despejam informações tresloucadamente, mesmo quando desligados.

Também é verdade que nessa "ciranda informacional" trafegam informações úteis e desprezíveis, que convivem numa (in)suportável (des)harmonia dentro dessa "nova" perspetiva informático-existencial da inebriante Pangeia de bits e bytes.

O que passa despercebido é que nós, principais fornecedores de energia desse "ensandecido ciclo de Carnot virtual", permanecemos quase sempre passiva e pacificamente envoltos nessa "febre do minuto computacional", como verdadeiros autómatos "repassadores" de conteúdos.

Assim sendo, abordar-se-á as políticas estabelecidas por associações estrangeiras de médicos concernentes aos cuidados com as informações profissionais veiculadas nas redes sociais, disponíveis a qualquer pessoa que possua, pelo menos, um telemóvel.

Considerando-se os indicadores do Journal of Health Informatics expressos na Tabela $1^{2}$ e que $96 \%$ da população portuguesa que utiliza as redes sociais fazem uso do Facebook, ${ }^{3}$ deve-se ter cautela para que não se quite a malograda fatura da negligência ou da ignorância com a reputação ou com o registo profissional.

Com isto, apresentam-se as determinações publicadas pela American Medical Association (AMA) - 2010, pela British Medical Association (BMA) - 2011, pela Australian Medical Association (AMA) e New Zealand Medical Association (NZMA) - 2011, e por fim, pelo Conselho Federal de Medicina do Brasil (CFM) - 2015.

Tabela 1 - Principais utilizações da internet pelos médicos

\begin{tabular}{ll}
\hline Busca de informações médicas & $71 \%$ \\
Incentivo à educação médica continuada & $65 \%$ \\
Acesso a protocolos e diretrizes clínicas & $50 \%$ \\
\hline
\end{tabular}

1. Serviço de Ortopedia. Hospital Vila Franca de Xira. Vila Franca de Xira. Portugal.

2. Departamento de Filosofia, Comunicação e Informação. Universidade de Coimbra. Coimbra. Portugal.

$\square$ Autor correspondente: Carlos Durão. drcarlosdurao@hotmail.com

Recebido: 03 de julho de 2017 - Aceite: 21 de maio de 2018 | Copyright $\odot$ Ordem dos Médicos 2018
Ressalva-se que Portugal também possui leis que regulamentam o assunto. A proteção legal inicia-se com o $n^{\circ}$ 6 , do Art. ${ }^{\circ} 35^{\circ},{ }^{4}$ da Constituição da República Portuguesa (CRP), passa pelo $n^{\circ} 1$, do Art. $^{\circ} 7^{\circ}$, da lei $n^{\circ} 67 / 98$, de 26 de Outubro, ${ }^{5}$ e se encerra com o Código Deontológico da Ordem dos Médicos - 2016, cujo fundamento primeiro deriva da conjugação do Art. $29^{\circ}$, com o $n^{\circ} 1$, do Art. $37^{\circ} .{ }^{6}$

\section{Evolução cronológica}

A entidade norte-americana (AMA) foi pioneira ao publicar, em Novembro de 2010, as suas orientações sob a égide de uma política institucional, ${ }^{7}$ estabelecendo princípios generalistas a serem observados pelos médicos e estudantes de Medicina, aconselhando-os a atentarem para a:

a) Manutenção da privacidade e da confidencialidade das informações relativas aos pacientes, abstendo-se de publicar na Internet quaisquer informações que identificam o paciente;

b) Utilização responsável da rede, com a adoção de configurações de segurança, visando diminuir o vazamento de informações próprias e dos pacientes;

c) Monitoração rotineira dos acessos às redes sociais, visando minimizar a disseminação de informações impróprias ou inverídicas acerca de si mesmo, escritas por terceiros;

d) Manutenção dos adequados limites da relação médico-paciente, aquando da interação via Internet, distinguindo os assuntos profissionais dos pessoais;

e) Vigilância do teor anti-profissional das publicações na Internet, com a obrigatoriedade de o autor remover ou corrigir a matéria demeritória, sob pena de ser denunciado às autoridades competentes em caso de recusa;

f) Consciencialização de que as informações mal-intencionadas veiculadas pela Internet podem afectar negativamente a reputação profissional, dada a perda de confiança dos pares e pacientes.

Em 2011, a BMA publicou a sua cartilha, ${ }^{8}$ porém, foi mais contundente. Os ingleses direcionaram as suas orientações para o comportamento nas redes sociais, citando, 
inclusive, uma das redes sociais mais utilizadas à época: o Facebook.

Desta forma, a BMA alertou os seus associados para:

a) Os média sociais podem distorcer a realidade da vida pública e profissional de um indivíduo;

b) Médicos e estudantes de Medicina devem, quando disponíveis, utilizar-se das ferramentas de configuração de privacidade, em face da vulnerabilidade das informações disponibilizadas na web;

c) O dever ético e legal de proteger a confidencialidade do paciente é igualmente aplicável à Internet e a quaisquer outros meios;

d) É inapropriado publicar comentários informais, pessoais ou depreciativos sobre pacientes ou colegas em fóruns públicos da Internet;

e) Os médicos e estudantes de Medicina que publicam online têm a obrigação ética de declarar quaisquer conflitos de interesse;

f) ABMA recomenda que os médicos e estudantes de Medicina não aceitem convites de amizade do Facebook provenientes de antigos ou actuais pacientes;

g) A lei [inglesa] de difamação pode ser aplicada aquando da publicação na web de comentário alusivo a assuntos pessoais ou profissionais de outrem;

h) Os médicos e estudantes de Medicina devem ter consciência da sua imagem online e de como esta pode afetar a sua reputação profissional.

Neste compasso e também em 2011, a AMA (Austrália) e NZMA publicaram conjuntamente o manual "Média social e profissão médica: um guia de profissionalismo online para médicos e estudantes de Medicina". 9

Não obstante a similitude com os manuais anteriores, as duas associações médicas do Novíssimo Mundo abordaram o tema de forma inovadora, uma vez que o enriqueceram com exemplos reais, e publicaram, descontraidamente, o questionário "Você já ...?", adiante transcrito:

Você já ...?

- Se "googlou" a si próprio? Então, pesquise o seu nome completo no Google e veja se sente confortável com os resultados apresentados;

- Procurou alguma informação relativa a um paciente ou a um colega de trabalho no Facebook? Então, reveja os seus posts antigos e perceba como são entendidos atualmente;

- Adicionou pacientes como amigos no Facebook?

- Adicionou pessoas do seu trabalho como amigos no Facebook?

- Publicou um comentário online que poderia ser considerado ofensivo?

- Se tornou membro ou seguidor de um grupo que pudesse ser considerado racista, sexista, violento ou detentor de qualquer outro demérito? Então, reveja todos os seus grupos e verifique se eles refletem a pessoa que é, e se exprimem os seus valores.

- Divulgou online fotos ou vídeos de si mesmo que não gostaria que os seus pacientes, empregadores ou colegas de trabalho vissem?

- Conferiu as suas configurações de privacidade no Facebook?

- Deparou-se com publicações online de amigos seus que pudessem gerar consequências negativas para eles? E alertou-os disto?

Ultrapassadas as determinações anglófonas, o CFM também publicou as suas regras por intermédio da Resolução CFM n² 2.126/2015, ${ }^{10}$ de 01 de Outubro de 2015, tendo sido taxativo na proibição de certos comportamentos em sites, blogs, Facebook, Instagram, YouTube, WhatsApp e similares.

\section{CONCLUSÃO}

Este artigo não defende a proibição da utilização das redes sociais por médicos e académicos de Medicina nem pretende impor regras de censura. Intenciona, no âmbito comportamental, alertar para a manutenção das tradicionais expectativas relativas à conduta médica neste contexto não-tradicional, ou seja, médicos e estudantes de Medicina possuem o dever de manter elevados padrões de conduta profissional em relação aos seus pacientes e pares, como sempre foi determinado e cumprido, inclusive nas redes sociais. Por isso, é que relembrar os cuidados relacionados com a divulgação de informações pessoais e profissionais na Internet, bem como os seus limites, é sempre valioso para que a rede não se transforme num instrumento anti-profissional "caçador de registos".

Nacional: Lisboa; 2016.

7. AMA-ASSN.org [https://www.ama-assn.org/]. Illinois: American Medical Association, 1995-2017. [consultado 2017 Abril 29]. Disponível em: https://mededu.jmir.org/article/downloadSuppFile/4886/28296.

8. BMA.org.uk [https://www.bma.org.uk/]. London: British Medical Association, 2011. [consultado 2017 Abril 29]. Disponivel em: http:// www.medschools.ac.uk/SiteCollectionDocuments/social_media_ guidance may2011.pdf.

9. AMA.com.au [https://ama.com.au] Camberra: Australian Medical Association, 2016. [consultado 2017 Abril 29]. Disponível em: https:// ama.com.au/sites/default/files/Social_Media_and_the_Medical_ Profession FINAL.pdf.

10. CFM.org.br [https://portal.cfm.org.br/] Brasília: Conselho Federal de Medicina, 2010-2017. [consultado 2017 Abril 29]. Disponível em: https:// sistemas.cfm.org.br/normas/visualizar/resolucoes/BR/2015/2126. 